\title{
CLÁUSULAS TAKE OR PAY, ORIGEN ESTADOUNIDENSE Y EFECTOS EN EL MERCADO CHILENO DE LA ENERGÍA
}

\section{TAKE OR PAY CLAUSES, US ORIGIN AND EFFECTS ON THE CHILEAN MARKET OF ENERGY}

Cristián Araya Maggi*

\section{RESUMEN}

El presente documento, describe el origen de la cláusula contractual conocida como take or pay bajo el Derecho estadunidense y en el contexto de la industria energética, revisando los casos de conflicto más significativos que ha presentado su uso e interpretación, para luego describir la regulación administrativa estadounidense surgida como resultado de tales conflictos, así como también la posterior incorporación de la cláusula a los contratos del mercado chileno de la energía y de qué manera esta puede influir en la determinación del despacho de las unidades generadoras, finalizando con una reseña de algunas discrepancias producidas y las recientes acciones del ente supervisor local.

Palabras clave: Take or pay, contrato, gas natural, mercado eléctrico, suministro de largo plazo, impracticability, jurisprudencia, imprevisión, costo marginal, despacho de generadoras.

\section{AbStRACT}

This paper describes the origin under the American law of the contractual clause known as take or pay in the context of the energy industry, and it reviews the most significant conflicting cases arising from its use and interpretation. It also provides a summary examination of the administrative

* Abogado Universidad Católica de Chile, LL.M. London School of Economics. Abogado Larraín \& Asociados. Dirección postal: Av. El Bosque $N^{\circ} 130$, piso 12, Santiago. Correo electrónico: caraya@larrain.cl. Artículo recibido el 29 de julio de 2016 y aceptado para su publicación el 13 de abril de 2017. 
regulation derived in America from the litigations, and later adoption of the covenant into the local Chilean contracts for supply to the energy market and how it may influence or affect the parameters to determine dispatch of the generating units, context in which scarce conflicting cases and finally the recent actions from the regulatory authority are studied.

Key words: Take or pay, contract, natural gas, energy market, long term supply, impracticability, precedents, impossibility, marginal cost, dispatch of electric generators.

\section{INTRODUCCIÓN}

De acuerdo con la teoría jurídica tradicional, el contrato suele definirse como un "acuerdo de voluntades de dos o más personas destinado a crear obligaciones"1. Para la teoría económica, por su parte, una de las funciones primordiales de los contratos es la asignación de los riesgos entre las partes involucradas, sobre todo de los que se prolongan en el tiempo, ya que el futuro es incierto. Estos generan lo que se denomina "intercambios diferidos", es decir, operaciones o, legalmente hablando, “obligaciones” que se 184 completan durante el transcurso de un plazo. El paso del tiempo entre la celebración y su ejecución genera incertidumbres o riesgos que solo son aminorados gracias a la fuerza obligatoria que les da la ley a los contratos ${ }^{2}$. Sin esa fuerza, faltarían los incentivos coercitivos para cumplir lo acordado. Esos dos aspectos constituyen el centro de la materia que nos ocupa.

El tema del presente artículo tiene su fuente en consecuencias económicas y cómo ellas afectan los intereses de las partes involucradas y, por lo tanto, tiene un influjo sustancial de esta disciplina en los términos aquí empleados, así como en las variables tratadas.

Por otra parte, si bien se hace referencia a aspectos regulatorios y se analizan respuestas de las autoridades administrativas bajo la forma de normas y ciertos mecanismos utilizados, este trabajo no tiene su foco en el tratamiento doctrinario del Derecho Eléctrico así como tampoco de ninguna rama del Derecho Administrativo o de mercados regulados, sino que más bien en la reseña de las implicancias económico-jurídicas que son causa o efecto de los riesgos de contratación en ciertas industrias energéticas, desde el punto de vista del Derecho Privado. En este sentido, cabe mencionar la ausencia de tratamiento de esta materia por parte de la doctrina nacional sobre Derecho Eléctrico.

${ }^{1}$ Véase Alessandri (1988), p. 6 y Diez-Picazo (1996), pp. 115-128.

${ }^{2}$ Véase Cooter \& Ulen (2008), p. 203 y Coderch (2009), pp. 11-14. 
Con el propósito que se menciona, iniciaremos este documento, describiendo los orígenes, objeto y evolución de la cláusula take or pay en el mercado de la energía de Estados Unidos. Al tener su surgimiento en la industria del gas natural, gran parte de esta obra tendrá referencia o se relacionará con dicho mercado, tanto en el caso estadounidense como en la experiencia chilena.

Lo anterior, incluyendo un análisis de los principales fundamentos de las acciones legales iniciadas en el país anglosajón, particularmente la commercial impracticability -símil a la teoría de la imprevisión en el Derecho chileno, en el que destaca la falta de jurisprudencia específica relativa a la aplicación de la cláusula en comento- para luego revisar el uso que se le ha dado en el mercado eléctrico de nuestro país.

Solo restan mis sinceras disculpas al lector que esperaba encontrarse con un análisis exegético o dogmático de la materia.

\section{EL CONTEXTO ESTADOUNIDENSE}

\section{Orígenes}

La incipiente industria del gas natural en Estados Unidos fue exceptuada de la creciente regulación federal que impuso la Ley de Comercio Interestatal $^{3}$. El surgimiento de la tecnología de gasoductos a alta presión (como resultado del desarrollo del acero de alta resistencia y de la soldadura eléctrica) y el rápido crecimiento de la red interestatal durante la década 1920, provocó tensiones de competencia entre la regulación de cada estado involucrado, con normas contradictorias entre Estados "compradores" versus "vendedores", y la regulación federal. Algunos de estos conflictos fueron sometidos a la decisión de la Corte Suprema de Estados Unidos, quien declaró inconstitucional la intervención regulatoria estatal bajo la reserva del comercio interestatal y estableció el principio según el cual los Estados no podían regular ventas de productos a ser revendidos o transportados en el comercio interestatal ${ }^{4}$.

${ }^{3}$ Ley promulgada en 1887 con el fin de regular la industria de los ferrocarriles y en particular sus prácticas monopólicas en el comercio interestatal. Su fundamento era la reserva constitucional que entregaba en forma exclusiva al congreso federal la facultad para regular el comercio interestatal, esto es, el intercambio de bienes y servicios entre, o a través de, distintos Estados (Commerce Clause). Con el tiempo, modificaciones de esta norma y nuevas leyes regularon otros medios de transporte dentro del concepto de Common Carrier (servicios de transporte regulados que se ofrecen al público general y deben prestarse en términos no discriminatorios), así como las telecomunicaciones y otros servicios públicos.

${ }^{4}$ Public Utilities Comm. v. Attleboro Steam \& Elec Co., (1927); Missouri v. Kansas Gas Co., (1924); Pennsylvania v. West Va., (1923). Citadas por Pierce (1988), p. 5. 
Por otro lado, el Congreso de Estados Unidos recibió numerosos reclamos e inquietudes de consumidores, distribuidores y productores, alegando una variedad de prácticas abusivas y discriminatorias por parte de los entonces "no regulados" gasoductos, lo que desembocó, primeramente, en la preparación de un completo reporte encomendado a la Federal Trade Commission $^{5}$-el que identificó como causa de tales eventos la existencia de monopolios naturales por la presencia de grandes economías de escala en la industria de los gasoductos- y a continuación, en la dictación de la Ley de Gas Natural de $1938^{6}$.

En el negocio de transporte por gasoductos se presentan en general grandes economías de escala en los costos fijos y bajos costos variables. Los costos decrecientes dieron a los primeros entrantes una ventaja que no derivaba de eficiencias. Por ello, las empresas establecidas en el mercado tenían el incentivo de disminuir sus precios al máximo posible, con el fin de excluir competidores. De esta manera, los gasoductos podían ejercer poder monopólico sobre los distribuidores y de monopsonio respecto de los productores?.

El propósito del legislador estadunidense con la dictación de la Ley de Gas Natural fue, primordialmente, llenar algunos vacíos legales generados como consecuencia de la jurisprudencia de la Corte Suprema que mencionamos más atrás, con regulación federal destinada a proteger a los consumidores de potenciales abusos del poder monopólico de los gasoductos. Conforme a esta ley, se reguló a los gasoductos interestatales, pero no a los productores, ni distribuidores de gas. El principal problema experimentado por el regulador en esos años fue la práctica de compraventas que realizaban los gasoductos a empresas productoras relacionadas. Los gasoductos podían "venderse" a un alto costo con el objetivo de obtener vía sus negocios no regulados, el retorno excesivo que la ley impedía en sus actividades reguladas ${ }^{8}$.

Como resultado, la Comisión intentó fijar controles a los precios de las compañías productoras relacionadas a los gasoductos, lo que fue disputado por estos, al considerar que se estaban excediendo las facultades

${ }^{5}$ Agencia estadounidense fundada en 1914 cuya principal función es supervisar las prácticas competitivas en los mercados e investigar potenciales fusiones con el objetivo de asegurarse que tales mercados funcionen de acuerdo con las preferencias de los consumidores y no a prácticas indebidas.

${ }^{6}$ Luego de intentos de someter a esta industria a la regulación de la Comisión de Valores (SEC) bajo las normas de la PUHCA de 1935, en la que sí se incluyó a las utilities eléctricas, donde se produjo un largo debate respecto de ciertas disposiciones que habrían dado a los gasoductos el carácter de Common Carriers.

${ }^{7}$ McArthur (1992), p. 359 y (1997) p. 7.

${ }^{8}$ Pierce (1988), pp. 6-7. 
que legalmente disponía el regulador. En el caso Interstate Natural Gas Co. v. Federal Power Commission de 1947, la Corte Suprema de Estados Unidos confirmó el criterio empleado por el regulador, sin fundamentar su decisión en el factor de relación con un mismo grupo económico entre las partes contratantes (productor-gasoducto) como era el argumento de la Comisión, sino que en consideraciones que podían ser igualmente aplicables para productores independientes. Por último, en 1954, la Corte Suprema de Estados Unidos en el caso Phillips Petroleum Co. v. Wisconsin, resolvió que el ente regulador de la época -hoy la $\mathrm{FERC}^{9}$ - estaba facultado para imponer controles a los precios en boca de pozo del gas natural de productores independientes para reventar en el comercio interestatal ${ }^{10}$.

A consecuencia de lo anterior, se desarrollaron dos mercados paralelos, uno interestatal regulado y otro intraestatal no regulado, con precios en este último que continuaron incrementándose, mientras que los precios pagados a los productores por los compradores de comercio interestatal permanecieron artificialmente bajos, generando en este déficit de suministro y cortes. Los bajos precios generaron desincentivos para la exploración y desarrollo de nuevas reservas, las cuales declinaron ${ }^{11}$.

A su vez, las tarifas fijadas por el regulador a los gasoductos interestatales permitían obtener una determinada tasa de retorno sobre el costo de capital, generando incentivos para invertir en instalaciones muy costosas, atendido que el total de las utilidades aumentaba con el mayor gasto en capital, además de eliminar incentivos para mantener ciertos costos bajos, ya que los gastos en gas eran traspasados a los clientes, y como si esto fuera poco, adicionalmente eso blindaba a los gasoductos de riesgos económicos, pues se les aseguraba la recuperación de su capital, más una tasa de retorno razonable ${ }^{12}$.

El aumento del déficit de producción derivó en cortes de suministro para clientes industriales y comerciales, lo que llevó al reemplazo del gas natural por otros combustibles cuatro veces más caros, situación que se exacerbó con el embargo de crudo de 1973 y, al mismo tiempo, a la adopción de políticas para disminuir la brecha entre los mercados, tales como fijación de precios más altos del gas producido por gasoductos o empresas relacionadas o aprobando aumentos de precio en cabeza de pozo para nuevas explotaciones de gas, acciones que demostraron ser tardías para el

${ }^{9}$ Federal Energy Regulatory Commission.

${ }^{10}$ Algunos consideran que esta sentencia es la fuente de la mayoría de los problemas de la industria del gas sufridos en la década de 1980, como resultado de décadas de precios regulados artificialmente bajos. McGrath (1984), p. 201. Véase Pierce (1988), p. 8.

${ }^{11}$ Uno de los efectos fue la concentración de la industria petroquímica dentro de los mismos estados productores, donde el adecuado suministro estaba asegurado. Se calcula que en la década de 1980 un 70\% estaba localizada en Texas y Louisiana.

${ }^{12}$ McArthur (1997), pp. 9-10. 
crudo invierno 1976-1977, el cual fue excesivamente largo y con el cierre de cientos de plantas productivas y escuelas ${ }^{13}$.

Esta crisis hizo pensar con más seriedad en fuentes alternativas de energía, como GNL y recursos disponibles en la región de Alaska y generó consenso en cuanto a la necesidad de desregular los precios en orden a estimular la exploración y producción, idea que fue recogida por la nueva Ley de Política de Gas Natural promulgada en 1978. Los precios se incrementaron, pero la demanda se contrajo. Simultáneamente se produjo un superávit de disponibilidad de gas, que en condiciones normales de mercado habría llevado los precios a la baja hasta que oferta y demanda se equilibraran. Las complejidades y rigideces del sistema regulatorio ${ }^{14}$, así como del esquema contractual de la industria, se conjugaron para frustrar lo anterior y derivar en la crisis que describimos en el acápite a continuación.

\section{Gasoductos y acceso abierto}

Para introducirnos en el campo de la cláusula take or pay, resulta importante entender el papel protagónico que han representado las empresas de transporte de gas en el mercado estadounidense.

Hasta principios de la década de 1980, los gasoductos no estaban sujetos 188 a una obligación de acceso abierto ${ }^{15}$ de su capacidad y reunían en una sola entidad las actividades de comercializador y transportista, de modo que estos prestaban servicios integrados o bundled services ${ }^{16}$. Desde la compra del gas en boca de pozo, su procesamiento, almacenamiento y transporte, hasta la venta al cliente final y, por ende, en la práctica eran propietarios de la totalidad del gas dentro de sus gasoductos ${ }^{17}$. En razón de lo anterior, las empresas de transporte eran los principales y mayores compradores frente a los productores y como veremos gozaban de una posición dominante en la industria.

Conforme a la doctrina, la principal manifestación de la regulación en materia económica en el mundo contemporáneo es la afectación de la propiedad privada a la voluntad de la ley, de modo que esta

${ }^{13}$ McGrath (1984), pp. 202-203.

${ }^{14}$ Llegó a comprender unas veintisiete categorías de precios distintos.

${ }^{15}$ En contraste, ya en 1906 el Congreso impuso el acceso abierto por ley a los oleoductos, con el fin de limitar el poder monopólico de la Standard Oil Company en el procesamiento y distribución de petróleo.

${ }^{16}$ MCArthur (1997), p. 14. Probablemente por su participación accionaria estadounidense, este modelo fue replicado en Chile por el proyecto de gasoducto transandino Transgas, la empresa competidora de GasAndes, que empleando la estructura contraria (unbundled) fue la que finalmente se adjudicó los contratos que aseguraron la construcción del primer gasoducto transfronterizo en la zona central de Chile.

${ }^{17}$ Véase McArthur (1992), pp. 394-395 y McArthur (1997), pp. 8-9. 
"se adentra (regulación interna) en la actividad económica, con el consiguiente desplazamiento de la autonomía de la voluntad entre oferentes y consumidores" ${ }^{\prime 18}$.

Mediante la ley, el Estado está limitando profundamente la naturaleza del derecho de propiedad clásico, expresado en sus facultades de uso, goce y disposición, en cuanto a la explotación económica de un bien ${ }^{19}$. Algunos, incluso, sostienen que aparece un nuevo tipo de propiedad vinculada por su destino, donde se separa dominio y uso ${ }^{20}$.

Este modelo de regulación, responde a la doctrina jurídica anglosajona de las "instalaciones esenciales", expresión de un principio del Common Law en virtud del cual se debe imponer el acceso abierto respecto de ciertas instalaciones, activos y propiedades que están afectadas por el interés público. De acuerdo con la teoría económica, las externalidades positivas que produce el acceso abierto a tales instalaciones o activos hace que sea socialmente deseable ${ }^{21}$.

El riesgo se presenta en casos donde se ejerza posición dominante o poder de mercado contrario a las normas de libre competencia por parte de una agente económico. Como señala una sentencia:

"la doctrina de las instalaciones esenciales impone responsabilidad cuando una firma, que controla una instalación esencial, niega a otra firma acceso razonable a un producto o servicio que la segunda debe obtener para poder competir con la primera" 22 .

Habiendo tenido su primer y mayor desarrollo en el sistema legal estadounidense, el que se produjo a partir de la aplicación que le dieron los tribunales de justicia, en los últimos años ha sido objeto de una corriente de críticas, circunstancia avalada por los últimos fallos de su Corte Suprema, no así por los tribunales de primera instancia de ese país. En el caso europeo, esta fue recogida expresamente en su tratado constitutivo y ha gozado de un desarrollo más sostenido ${ }^{23}$.

En síntesis, para aplicar la doctrina, se consideran los siguientes requisitos fundamentales:

${ }^{18}$ Sepúlveda (2010), p. 11.

${ }^{19}$ Tomás De la Quadra-Salcedo, "Las palabras y las cosas", citado por Sepúlveda (2010), p. 11.

${ }^{20}$ Rafael Caballero y Gaspar Ariño, citados por Sepúlveda (2010) p. 12.

${ }^{21}$ Frischmann (2006), pp. 4-5.

${ }^{22}$ Alaska Airlines, Inc. v. United Airlines, Inc., (1991), citado por Pitofsky et al. (2002), p. 446. Traducción del autor.

${ }^{23}$ Para un completo análisis de los orígenes, casos más relevantes y jurisprudencia chilena, véase Montt y Nehme (2009); Ugarte (2013) y Rencoret (2010). 
i) que haya un monopolista que goza de una posición dominante al controlar una instalación esencial;

ii) el monopolista ejerce dicho poder negándole el acceso a un competidor $y$

iii) esa negativa afecta la competencia en el mercado y carece de toda justificación legítima (i.e. que no existan restricciones técnicas para dar tal acceso), o se manifiesta en términos arbitrariamente discriminatorios.

En el caso de la jurisprudencia estadounidense y europea, se exige, además, que el competidor que busca acceso del monopolista se vea imposibilitado de duplicar razonablemente esa instalación, elemento que no todos los autores ven en las decisiones del Tribunal de la Libre Competencia nacional ${ }^{24}$.

Por otra parte, el principio del acceso abierto ha sido también recogido legalmente en Chile, con ejemplos paradigmáticos en la industria de la energía. En efecto, desde 1995 se impone a los concesionarios de transporte de gas de red la obligación de operar bajo el sistema de "acceso abierto" respecto del ofrecimiento de su capacidad disponible. Casi diez años después (2004), la Ley General de Servicios Eléctricos también incorporó esta regla en relación con ciertas instalaciones de transmisión de electricidad, de modo que puedan ser utilizadas por terceros en términos no discriminatorios ${ }^{25}$.

Como muchos gasoductos sufrieron la falta de gas durante la crisis de comienzos de la década de 1970, fueron duramente cuestionados por las autoridades y consumidores estadounidenses. Además, los precios regulados del mercado interestatal empezaron a caer por debajo del precio no regulado del mercado local (intraestatal), hacia el cual naturalmente dirigieron sus ventas los productores buscando mejores condiciones y ocasionando una escasez para los gasoductos interestatales. Entonces, esto obligó a los compradores en este mercado a ofrecer mejores precios y a comprometerse a tomar altas cantidades de producción, para asegurar suministro ${ }^{26}$.

La Ley de Política de Gas Natural estaba llamada a corregir la distorsión de precios y a poner los incentivos para crear un solo mercado unificado, competitivo y desregulado ${ }^{27}$. Al momento de su promulgación, los gasoductos no tenían incentivos suficientes para preocuparse por los precios, ya que su prioridad era asegurar suministro estable y, además, porque

${ }^{24}$ Véase Montt y Nehme (2009), pp. 27-34 y Rencoret (2010), pp. 135-145.

${ }^{25}$ DS N 263 de 1995, que aprobó el Reglamento sobre Concesiones Provisionales y Definitivas para la Distribución y el Transporte de Gas, y DFL N 4 de 2007, que fijó el texto refundido de la Ley General de Servicios Eléctricos (originalmente de 1982).

${ }^{26}$ McArthur (1992), p. 361.

${ }^{27}$ Una revisión de las principales causas que se adjudican al fracaso de esta ley para impedir los efectos de la crisis, principalmente errores de diagnóstico del Congreso de Estados Unidos, puede verse en Pierce (1988), pp. 12-16. 
regulatoriamente se les permitía traspasar todos sus costos "prudentes" a los clientes finales. Al mismo tiempo, los precios de mercado del gas iban en alza y se especulaba sobre una inminente liberalización de varios precios regulados, lo que hizo redoblar los esfuerzos de los gasoductos para suscribir nuevos contratos, asumiendo compromisos considerables de take or pay, riesgos de largo plazo y altos precios de estructura muy rígida ${ }^{28}$.

Pues bien, a principios de la década de 1980 se produjo una desaceleración económica importante, los precios del gas siguieron escalando, las diferencias en la OPEC causaron una disminución del precio del crudo mundial y esto llevó a muchos clientes a sustituir el gas por otros combustibles más competitivos. A lo anterior, se sumaron inviernos más benignos y mayor competencia hidroeléctrica, lo que redujo aún más la demanda y los incentivos legales, por su lado, hicieron aumentar la oferta. Como efecto, dentro de unos años los gasoductos estuvieron en condiciones de adquirir gas natural muy barato, pero ellos estuvieron constreñidos a asumir la carga que representaban sus contratos take or pay de larga duración y a altos precios ${ }^{29}$.

\section{Surgimiento de la cláusula}

El surgimiento de este mecanismo de take or pay respondió a necesidades de la industria.

En los inicios, los contratos entre productores y compradores de gas natural no requerían algún consumo mínimo. Como consecuencia, pozos en plena etapa productiva a menudo quedaban impedidos de hacer frente a sus costos en forma periódica y veían, incluso, afectada su capacidad de financiamiento, ya que los flujos de caja que presentaban eran inciertos. Adicionalmente, gran parte de los contratos estipulaban derechos de venta exclusiva, que prohibían al productor buscar nuevos clientes.

Por su parte, los compradores deseaban una abundante disponibilidad de reservas para evitar el riesgo de falta de gas en periodos de peak de consumo y sin la obligación de compra mínima podían requerir el suministro conforme a su conveniencia. De esta forma, al quedar privados de ingresos por ventas, los productores no podían recuperar sus costos de exploración, perforación y operación de sus pozos. Este problema se solucionó con la adopción de la cláusula take or pay ${ }^{30}$.

${ }^{28}$ Algunos autores sostienen que la crisis no se habría producido si los contratos de compra hubieran considerado una estructura de precios ajustables conforme a la variación de mercado, que hubiera permitido a los gasoductos disminuir sus precios conforme lo hacían los del mercado de venta final. McArThur (1992), pp. 361-362.

${ }^{29}$ McArthur (1992), pp. 362-363.

30 "Prior to 1960, fluctuations in the demand for natural gas created financial hardships for natural gas producers. The demand for natural gas increases substantially during 
El propósito de estas cláusulas fue compensar al productor por estar disponible permanentemente a suministrar las cantidades máximas contratadas y, al mismo tiempo, eliminar el riesgo del productor de limitar sus ingresos a las cantidades eventualmente variables que el comprador pueda solicitar de tiempo en tiempo ${ }^{31}$.

$\mathrm{Su}$ objetivo, pues, fue asignar los riesgos entre las partes contratantes. En virtud de ella, el comprador estaba asumiendo el riesgo de deterioro de su propio mercado de venta y el vendedor, por su parte, se aseguraba recibir un determinado ingreso anual por la duración del contrato. En otras palabras, permite la distribución del riesgo de fluctuación de los precios del producto en el mercado, haciendo que ambas partes y no solo una de ellas asuma una porción de dicho riesgo. En este sentido, estos contratos presentan una analogía con los mercados de futuros.

Particularmente en contratos donde se fija el precio, en ausencia de esta estipulación, tal riesgo lo asume el vendedor, pues estaría obligado a vender al precio acordado, aunque sea menor, en caso que haya un alza en el mercado y, en el evento que el precio de mercado disminuya, el comprador podría dejar de tomar el producto si la reventa del mismo deja de ser rentable por tener que comprar el suministro a un precio más caro que el de mercado. Esta cláusula aseguraba que, aun cuando el precio de mercado bajara respecto del precio del contrato, el comprador tendría que 192 seguir pagando una mínima cantidad al productor, independientemente de si el gasoducto tomaba y vendía el gas o $\mathrm{no}^{32}$.

Típicamente, una estipulación take or pay obliga al comprador a adquirir una cantidad mínima del producto o servicio en cada periodo, por lo general anual o, alternativamente, a pagar esa mínima cantidad aun cuando no la haya tomado o aceptado recibirla. En el mercado del gas natural, históricamente esa cantidad mínima ha estado entre el $70 \%$ y $90 \% 0^{33}$. Si bien esta no es una cláusula exclusiva de los contratos en la industria energética, es en ella donde se ha producido su desarrollo sustantivo y desde donde su uso se ha propagado hacia otros países como el nuestro.

winter months because natural gas is used for commercial and residential heating. To handle winter peaks, pipelines acquired an overabundance of production capacity from producers. In addition, pipelines insisted that producers exclusively dedicate particular wells or reservoirs to the pipeline in the gas purchase contract. Pipelines, however, were under no obligation to purchase gas from the producers. As a result, during periods of low demand for natural gas pipelines purchased less than full production from producers, if any gas at all. Producers, unable to sell the gas to other purchasers because of the exclusive dedication clause, suffered from lost gas sales revenue. In many cases, producers were unable to recover drilling, exploration and operation costs". Medina (1991), p. 286.

${ }^{31}$ Medina et al. (1986), p. 190.

${ }^{32}$ Op. cit., p. 188; MCARTHur (1992), p. 359; COFFEY (1999), pp. 153-155; LOOPER (2011), p. 304.

${ }^{33}$ En sus orígenes, los volúmenes mínimos se encontraban vinculados a la reserva de un pozo o a su capacidad de producción de gas. Medina et al. (1986), p. 188. 
En la mayoría de los casos los contratos prevén en paralelo un derecho de recuperación del producto pagado, pero no recibido, denominado make-up, conforme al cual el comprador puede tomar cantidades a futuro, con una serie de restricciones en cuanto a plazo, precio y condiciones previas $^{34}$. El plazo limitado para poder recuperar el gas ya pagado, pero no tomado sería una de las raíces de los inconvenientes generados a los gasoductos en el mercado, ya que si estos no estaban en condiciones de tomar suficientes volúmenes de gas -luego de cumplir con la obligación de recibir las cantidades mínimas comprometidas- las cantidades pagadas por anticipado jamás serían recuperadas.

Estas cláusulas, en parte, fueron un subproducto del sistema regulatorio de control de precios y del compromiso de los gasoductos para asegurar el suministro futuro. Durante los años de déficit de suministro, los gasoductos interestatales que no podían ofertar por precio, en razón del control de precios existente, competían entonces por los términos contractuales, como las cláusulas take or pay, las cuales eran atractivas para los productores de gas en razón del compromiso de largo plazo que significa$\operatorname{ban}^{35}$.

\section{La crisis}

Como consecuencia de la fuerte declinación del precio de mercado del gas, los gasoductos vieron que no era rentable la reventa a los clientes finales del suministro que ellos se encontraban obligados a pagar contractualmente, lo que indujo a muchos de ellos a dejar de honrar sus compromisos contractuales. Como era de esperar, esto derivó en un gran número de litigios entre productores y gasoductos conocida como la "Take or Pay Crisis"36. Es interesante repasar las principales argumentaciones de las partes en estos litigios ${ }^{37}$.

\section{a) La fuerza mayor}

Una de las alegaciones centrales de los gasoductos fue que había surgido un evento de fuerza mayor, causal de liberación de responsabilidad siempre presente en los contratos, aduciendo que la caída en las condiciones de mercado y las resoluciones reglamentarias de los entes fiscalizadores

${ }^{34}$ Por ejemplo, las cantidades recuperadas deben solicitarse en forma adicional y por sobre las cantidades mínimas requeridas como base por el contrato.

${ }^{35}$ McGrath (1984), p. 207.

${ }^{36}$ Para 1989, la FERC calculaba que más de US\$44.000.000.000 en obligaciones take or pay habían sido objeto de acuerdos de transacción entre las partes en conflicto.

${ }^{37}$ Para una descripción detallada de los casos y argumentos, véase Medina et al. (1986) y McArThur (1992). 
eran eventos fuera de su control y, por lo tanto, los gasoductos debían ser excusados de su obligación por cuanto eso no les permitía revender el gas que se habían comprometido a adquirir.

En la mayoría de los casos, este argumento fue rechazado por los tribunales, señalando que las variaciones de oferta y demanda y los cambios regulatorios eran factores normales a considerar en cualquier negocio, en especial en un mercado volátil como el del gas y que, por consiguiente, eran riesgos suficientemente previsibles. De lo contrario, en la práctica, estos contratos se harían inexigibles ${ }^{38}$. En uno de los casos, el tribunal remarcó la distinción entre "baja" de mercado (simple pérdida de rentabilidad) y "falta" de mercado (inexistencia de demanda). Adicionalmente, los tribunales precisaron que en ningún caso la "inhabilidad financiera" de los gasoductos podría considerarse como evento de fuerza mayor ${ }^{39}$.

\section{b) Commercial impracticability}

La doctrina de commercial impracticability es un desarrollo jurisprudencial del Derecho estadounidense que, además, ha sido reconocido legalmente con su incorporación en el $U C C^{40}$. En virtud de esta doctrina, se puede excusar el cumplimiento de su obligación a aquella parte de un contrato que ha sufrido un riesgo que no era razonablemente previsible y que no 194 fue asumido en forma expresa por ella, el cual produce un cambio sustancial en las condiciones originalmente consideradas en el contrato (basic assumptions) y, a su vez, genera un costo, dificultad o perjuicio extremo para alguna de las partes. En general, los tribunales aplican un estándar objetivo para determinar la previsibilidad, esto es, no se busca establecer si el hecho fue en efecto previsto, sino que sí pudo razonablemente haberse previsto bajo las circunstancias dadas, ejercicio que se realiza en forma previa a definir si el cumplimiento se hizo impracticable ${ }^{41}$.

Como sabemos, la imprevisión, símil en nuestro Derecho de la Institución del impracticability estadounidense, no es reconocida expresamente por la ley chilena, ni por los tribunales ordinarios (a diferencia de lo que

${ }^{38}$ Preston Oil v. Transcontinental Gas Pipeline Corp. (1986), Golsen v. ONG Western Inc (1988) y Hanover Petroleum Co v. Tenneco (1988). Un fallo a favor de los gasoductos es Atlantic Richfield Co. v. ANR Pipeline Co. (1989). Citados por McArthur (1992), pp. 367, 368, 370 y 381.

39 "The best reading of a take-or-pay promise is that financial inability cannot be a defense in any event. The pipeline's promise is a guarantee of a fixed stream of revenue... They guaranteed payments because they expected to make money selling producers' gas and the world hasn't turned out as they expected", citado por MCARTHur (1992), pp. 377-378.

${ }^{40}$ UCC Section 2-615.

${ }^{41}$ Para un completo y detallado estudio sobre esta materia, véase Momberg (2011), pp. 140-184. 
ha sucedido con algunos casos arbitrales) y su aplicación tampoco es pacífica entre la doctrina. En general, la doctrina en Chile exige las siguientes condiciones para su aplicación:

i) Al igual que en el caso estadounidense, debe producirse un evento que no era razonablemente previsible al momento de celebrar el contrato;

ii) El evento tiene que hacer el cumplimiento de la parte afectada excesivamente oneroso, alterando en forma sustantiva el equilibrio económico del contrato;

iii) El evento no debe ser imputable a negligencia o dolo de la parte afectada y

iv) Solo sería aplicable a contratos de tracto sucesivo y conmutativos ${ }^{42}$.

Los litigios en que esta doctrina fue argumentada por los gasoductos y rechazada por los jueces estadounidenses, tienen su fundamento en que no es posible excusar el incumplimiento cuando la contraparte ha asumido el riesgo de mercado, ya sea expresamente o por aplicación de la costumbre y, por tanto, se entendió incluida como parte de las condiciones esenciales del contrato, esto es, en estos casos, que el riesgo de mercado era asumido por el comprador (gasoductos). La aplicación de la cláusula take or pay, entonces, no quedaba sujeta a la condición suspensiva que el comprador quiera tomar, esté en condiciones de tomar o pueda revender el producto ${ }^{43}$. Otros casos alegados como precedentes por los compradores fueron considerados muy alejados de las circunstancias presentes en los casos de conflictos take or pay $y^{44}$.

${ }^{42}$ Momberg (2011), pp. 96-116. Análisis del caso arbitral destacado Gasatacama v. Elecda et al (2008), puede verse en BAHAMONDEZ (2008).

${ }^{43}$ McArthur (1992), pp. 414-417, citando comentarios 4 y 8 al UCC2-615, la sección 261 del Restatement of Contracts y los siguientes casos: Challenger Minerals Inc v. Southern Natural Gas Co (1986), Northern Indiana Public Services Co v. Carbon County Coal Co (1986).

${ }^{44}$ Ejemplos de esto son: International Minerals \& Chemicals Corp. v. Llano Inc. (1985), en el que el comprador se encontraba imposibilitado de cumplir sin tener que cerrar su mina, no había otra manera de cumplir. En cambio, un gasoducto siempre podía tomar y vender el gas, aunque fuera a pérdida. Eastern Airlines Inc v. McDonnell Douglas Corp. (1976), en el que se excusó el incumplimiento por normativas en situación de guerra que obligaban al productor a dar prioridad de entrega de artefactos para fines militares y cuya excusa estaba expresamente prevista en el contrato y Aluminum Co of America v. Essex Group Inc. (1980), en el que el tribunal buscaba mantener el equilibrio entre las partes, impidiendo una ganancia excesiva del comprador frente a una pérdida sustancial por el vendedor, situación que no se daba en los casos de take or pay, pues en estos la mayor pérdida del comprador no significaba nunca una ganancia enorme para el vendedor, sino que simplemente recibir el precio acordado. 


\section{c) Determinación de daños}

Otro aspecto de discusión relevante tenía relación con determinar la forma correcta de medir los daños reclamados, como resultado de las diferentes interpretaciones de los tribunales en cuanto al método a aplicar.

Algunos consideraban que la obligación de take or pay es de cumplimiento estricto $y$, por ende, fuerza a la parte incumplidora a pagar el total de las cantidades comprometidas bajo el contrato. Otros, en cambio, interpretaron la cláusula como una obligación alternativa del comprador, que lo obliga a pagar la diferencia entre el precio de mercado en la fecha y lugar de entrega, y el precio bajo el contrato, más daños indirectos ${ }^{45}$, pero existiendo en este último caso diferentes normas aplicables bajo el $U C C$ que podían derivar en interpretaciones contrapuestas. Conforme a la segunda alternativa, el vendedor mantiene la propiedad sobre el producto no pagado por el comprador y este debe pagar la diferencia entre el precio del contrato y el de mercado, constituyendo la tendencia mayoritaria de los tribunales.

En un fallo minoritario la Corte sostuvo que otras disposiciones del $U C C$ permitían a las partes fijar métodos de determinación de daños distintos en sustitución de la norma residual, fundando su sentencia en la función distribuidora de riesgos de la cláusula take or pay, ya que el comprador al 196 celebrar el contrato asume el riesgo de tener que pagar la cantidad mínima comprometida, así como también en el concepto que los pagos en tal caso no corresponden al precio de una compraventa, sino que a pagos por el derecho de opción de tomar el gas durante un plazo limitado en el futuro. Adicionalmente, razonó la Corte, atendido que es posible bajo el contrato que el comprador pague y nunca reciba el gas, el contrato no puede clasificarse como una simple compraventa, sino como un cumplimiento alternativo, de modo que deviene en dicho caso en una obligación monetaria directa ${ }^{46}$.

Por otra parte, ambas tendencias rechazan categorizar a la obligación como una cláusula penal, por cuanto al ser la obligación de take or pay una de cumplimiento alternativo, se podía distinguir de una cláusula penal. El razonamiento es que la cláusula penal requiere un pago en caso de incumplimiento, en cambio, la obligación alternativa exige un pago ya sea haya incumplimiento del comprador o no.

${ }^{45}$ Este es el remedio prescrito por la Sección 2-708 del UCC, cuerpo de codificación de las normas de comercio uniforme de Estados Unidos.

${ }^{46}$ Colorado Interstate Gas Co, v. Chemco Inc (1992), citado por Coffey (1999), pp. 160-164. 


\section{Regulación de la industria}

En un contexto en que la ventaja competitiva de la industria del gas estaba asegurada por precios regulados artificialmente bajos y existía una demanda que por regla general superaba a la oferta, proteger la oferta y las reservas constituían los objetivos principales ${ }^{47}$.

Si bien la Ley de Política de Gas Natural estaba destinada a liberalizar el mercado del gas natural, no fue sino el impulso de la administración central, a través de la agencia reguladora (FERC) quien llevó adelante acciones más sustantivas de desregulación, las cuales tomaron cuerpo principalmente por intermedio de resoluciones denominadas "Orders" y el principal empuje para ello fue la crisis de los contratos take or pay, ya que las disputas revelaron profundos problemas de la estructura regulatoria imperante.

La primera de estas resoluciones fue la "Order 380", mediante la cual se dispuso la anulación de obligaciones de pago mínimo que los gasoductos imponían a sus clientes finales, al considerar que generaban una injusta barrera a la competencia, pues inhibía a los clientes a comprar a otro proveedor al estar obligado a efectuar un pago periódico, utilizara el gas o no. En el fondo era un compromiso similar a las obligaciones de take or pay aguas arriba. La norma, sin embargo, dejaba vigente la recuperación de los costos fijos razonables mediante su traspaso a los clientes finales ${ }^{48}$.

Posteriormente, la "Order 436" de 1985, corrigió un punto no resuelto por la "380". Muchos productores y plantas industriales no tenían la posibilidad de poner u obtener gas en el mercado, por cuanto los gasoductos mantuvieron el control sobre el transporte y podían negarse a transportar gas de terceros en sus instalaciones. La " 436 " trajo consigo la obligación de acceso abierto para los gasoductos en términos no discriminatorios respecto de terceros, forzando así la apertura de una instalación esencial para el mercado del gas natural. Tardaría una década para que este movimiento se trasladara a la apertura de las líneas de distribución eléctrica en Estados Unidos.

Pero eso no fue todo, la orden también permitió a los clientes finales que hubieran contratado cantidades fijas de suministro de gas, convertir esos derechos para utilizarlos en transporte firme. De esta manera, se separaron los papeles de comercializador y transportista que hasta entonces mantuvieron combinados los gasoductos y que les permitía proveer el servicio único de "venta de gas transportado". Para hacer esto, los gasoductos debían producir o adquirir el gas natural, procesarlo, almacenarlo y

${ }^{47}$ McGrath (1984), p. 197.

${ }^{48}$ McArthur (1992), pp. 389-393. 
transportarlo en sus instalaciones, todo por una sola tarifa total. Como consecuencia, se impidió que los gasoductos pudieran utilizar su posición monopólica en el transporte de gas frente a los productores, estos pudieron vender su gas directamente a clientes finales y estos, a su vez, pudieron competir con los gasoductos en la compra directa de gas en boca de pozo ${ }^{49}$.

El año 1989, el Congreso de Estados Unidos aprobó una ley modificatoria de la Ley de Política de Gas Natural (la Natural Gas Wellhead Decontrol $A c t$ ) que eliminó progresivamente los controles de precios a la primera venta $^{50}$, hasta hacerlo en forma completa a partir del 1 de enero de 1993.

\section{GNL}

Otro ámbito importante y relacionado donde por sus similitudes se adoptó el uso habitual de cláusulas take or pay fue el mercado cada vez más desarrollado del GNL, cuya evolución vale la pena revisar someramente ${ }^{51}$.

En relación con la industria del GNL, esta por mucho tiempo fue vista como una fuente de alto costo de gas natural, hasta el momento en que el suministro local empezó a escasear. La predecesora de la FERC (la Federal Power Commission) aprobó la primera solicitud de construcción de un terminal e importación de largo plazo de GNL, en marzo de 1972, en el contexto de cortes masivos de suministro por parte de seis gasoductos ocurridos un mes antes. Un total de cuatro terminales fueron autorizados para construirse y operar en los años venideros, pero, una vez disipada la escasez de gas natural a fines de la misma década, el ánimo cambió significativamente impulsado por el aumento de precio también experimentado por el combustible, comparado con el gas natural doméstico.

Como consecuencia, la mayoría de los terminales dejaron de operar y varios cerraron sus puertas por un largo periodo y no volvieron a reactivarse hasta dos décadas después ${ }^{52}$. El resurgimiento, como era de prever, también siguió la evolución de los precios de GNL que en el año 2000, por primera vez desde 1980, volvió a quedar por debajo del gas natural

${ }^{49}$ Véase McArthur (1997), pp. 13-25; McArthur (1992), pp. 393-398.

${ }^{50}$ Primera venta en sus términos en inglés first sales, corresponde a cualquier venta de gas de un productor a un gasoducto, empresa distribuidora local o consumidor final, o cualquier venta en una cadena de operaciones que sea previa a la venta a algún gasoducto, empresa distribuidora local o consumidor final.

${ }^{51} \mathrm{El} \mathrm{GNL}$ es gas natural que mediante un proceso criogénico se somete a muy bajas temperaturas para llegar a su punto de ebullición, pasando de su estado gaseoso a líquido, lo cual permite su transporte en medios distintos y más flexibles que los gasoductos, limitados por su alcance geográfico. Su principal ventaja es que no depende de una fuente única de suministro.

${ }^{52}$ Este es el caso de Cameron LNG Terminal, Hackberry, Louisiana, citado por KNOWLES (2003), pp. 296-298. 
importado por gasoductos y también dada la creciente demanda que se proyectaba por el aumento en el uso de este combustible más limpio en la generación de electricidad derivada de la derogación de ciertas restricciones legales al uso de gas natural en esa industria ${ }^{53}$. Del mismo modo, contribuyó la promulgación de requisitos de calidad de aire más estrictos en la década de 1990 .

La base de la reglamentación de esta industria también se encuentra en la Ley de Gas Natural cuya Sección 3 dispone que ninguna persona exportará ni importará gas natural desde o hacia Estados Unidos, sin la previa autorización de la Comisión y en la medida que esto no se oponga al interés público. Siguiendo el criterio de liberalización imperante, la Comisión dio a los terminales de GNL el mismo tratamiento que a un gasoducto interestatal, de modo que se les exigía someter a aprobación su esquema tarifario, quedando sujetos a la política de acceso abierto, haciendo que los nuevos terminales o expansiones existentes llamaran a open season para ofrecer su capacidad, criterio que varió con posterioridad y que fue recogido en las modificaciones legales subsiguientes como veremos ${ }^{54}$.

El cambio más significativo y explícito en las políticas de la Comisión se dio en 2002 con la denominada "Decisión Hackberry", al aprobar el desarrollo de un terminal sin exigir que ofreciera sus servicios en términos de acceso abierto, ni sujeto a un determinado esquema de tarifas aprobadas por la autoridad, sino que a precio de mercado. Lo anterior, sobre la base de las circunstancias expuestas por el proyecto para el ofrecimiento y contratación de su capacidad, así como en el entendido que la función regulatoria era incentivar la inversión y la competencia en el mercado, de modo que no debería haber un control de precios en el terminal sino hasta que el GNL regasificado se inyectara a las instalaciones de los gasoductos interestatales. La Comisión, asimismo, consideró que los terminales de GNL deberían tratarse como instalaciones de producción ${ }^{55}$.

${ }^{53}$ PIFUA de 1978, que prohibía el uso de gas natural en diversas aplicaciones industriales y de generación.

${ }^{54}$ En materia de fijación tarifaria, por ejemplo, respecto de una solicitud sobre los costos de expansión del terminal de Elba Island, Ga, la FERC sostuvo que no correspondía un esquema de costo incremental sino del tipo roll-in, en casos en que el costo de la expansión es menor al de las instalaciones originales, pues los clientes existentes estarían subsidiando a los nuevos. “...incremental rates are not appropriate when inexpensive expansibility is made posible because of earlier, costly construction, since the existing customers bear the cost of the earlier most costly construction in their rates, and incremental pricing could result in the new customers receiving a subsidy from the existing customers because the new customers would not face the full cost of the construction that makes their new service posible. In such cases, rolled-in rates are indicated”. KNOwLES (2003), pp. 307 y 310.

${ }^{55}$ KNOWLes (2003), pp. 310-314. 
Con posterioridad a este cambio, sin embargo, aún quedaron aspectos no resueltos y sujetos a disputa o interpretación. Uno de los principales fue la divergencia sobre competencia entre la Comisión y los Estados individuales, la cual se vio reflejada en el caso de 2004 Sound Energy Solutions, donde el ente regulador estatal de California cuestionó fuertemente la competencia de la FERC, argumentando que solo tenía facultades para pronunciarse respecto a materias de importación de gas, pero no en cuanto a la ubicación, construcción y operación de los terminales, la cual quedaba entregada al estado respectivo, fundamentado especialmente en el hecho que el proyecto en cuestión solo procesaría GNL para ser consumido en su totalidad dentro del mismo Estado de California, y, en consecuencia, no se trataba de comercio interestatal ${ }^{56}$.

Si bien la Comisión rechazó por completo la demanda, la cuestión de jurisdicción solo quedó zanjada definitivamente en 2005 con la dictación de la reforma a la Ley de Gas Natural denominada Energy Policy Act, que entregó sin ambigüedades y en forma exclusiva a la FERC la autoridad para aprobar o denegar cualquier solicitud para la instalación, construcción, expansión y operación de terminales de GNL en tierra ${ }^{57}$, y adicionalmente codificó la política adoptada por la Comisión en la Decisión Hackberry $^{58}$.

\section{El caso de los generadores eólicos ¿La nueva crisis take or pay?}

En forma similar a los productores de gas natural durante los decenios 1970 y 1980, a comienzos de esta década diversos generadores eólicos en Texas celebraron contratos de suministro de electricidad de largo plazo con empresas distribuidoras, en condiciones take or pay y a un precio fijo establecido en los respectivos acuerdos.

A diferencia del gas natural, la electricidad no tomada no puede almacenarse y ser revendida más adelante, lo que dejaría a los generadores sin la posibilidad de recuperar sus pérdidas, ni aun parcialmente. Por esta razón, en el evento de producirse algún litigio por incumplimiento de contrato, los perjuicios serían considerables y los tribunales se verían probablemente forzados a conceder a los generadores indemnizaciones

${ }^{56}$ LuTE (2007), pp. 642-644.

${ }^{57}$ Esta misma norma es la que más adelante estipula que la exportación o importación de gas natural hacia o desde una nación con la cual exista un acuerdo de libre comercio que requiera dar tratamiento nacional en el comercio de gas natural, será considerada como congruente con el interés público y, por ende, las solicitudes respectivas deberán autorizarse sin demora. Traducción del autor.

${ }^{58}$ LuTE (2007), pp. 644-647. 
suficientes para cubrir sus costos medios que, en el caso de productores eólicos, en la práctica corresponderían casi únicamente a sus costos fijos. De no ser así, se generaría un incentivo perverso a los distribuidores-compradores para incumplir sus contratos y se estaría entregando una fuerte señal a los generadores para no invertir ${ }^{59}$.

No obstante su costo marginal, igual o cercano a cero, los generadores eólicos en el referido mercado no han desplazado a los que utilizan fuentes convencionales de combustibles por dos razones:

i) su intermitencia y

ii) porque recién estaban comenzando a recuperar sus costos de capital

y, por lo tanto, solo eran competitivos gracias a los subsidios estatales y al precio superior del gas natural.

En estos casos, la cláusula take or pay cumple la misma función que habíamos visto en el mercado del gas natural, esto es, incentivar la inversión en generación de electricidad por la vía de distribuir los riesgos de mercado, de modo que el productor tenga garantizados sus costos de capital $^{60}$.

Como sostiene el autor citado, en un escenario donde se conjuguen diversos factores, podría generarse un problema tan grave como la crisis pasada, una "tormenta perfecta" que afectaría significativamente la demanda de electricidad producida por los generadores eólicos, como consecuencia del impacto negativo en sus precios. Lo anterior podría situar a los clientes distribuidores en un escenario en que resultaría más beneficioso incumplir los contratos de largo plazo y arriesgar demandas de parte de los generadores, que continuar pagando el compromiso take or pay, aun sin la posibilidad de hacer retiros de electricidad ${ }^{61}$.

Uno de tales factores es el aumento de la oferta prevista como resultado de la incorporación de nuevas redes de transmisión. Un segundo, es la creciente y cada vez más abundante producción de gas de esquisto (shale gas) y la importación de gas desde Alaska. El tercero, es el creciente uso de otros combustibles alternativos, como carbón ${ }^{62}$.

En razón de lo anterior, generadores y compradores, aprendiendo la lección de la historia pasada, deberían diseñar estipulaciones que permitieran flexibilizar y hacer ajustes a las condiciones de precio y entrega para adecuarse a las variaciones sistémicas del mercado y, de este modo, aminorar eventuales consecuencias nefastas para ambas partes en el futuro.

\footnotetext{
${ }^{59}$ LOOPER (2011), pp. 305-312.

${ }^{60}$ Op. cit., pp. 309.

${ }^{61}$ Op. cit., pp. 338-341.

${ }^{62}$ Op. cit., pp. 320-340.
} 


\section{EXPERIENCIA EN EL MERCADO CHILENO DE ENERGÍA}

\section{Llegada del gas natural. Herencia de take or pay}

Si bien el gas natural se utiliza como combustible en la Región de Magallanes desde hace décadas, fue recién a fines del decenio 1990 que su consumo se pudo hacer realidad en las demás zonas del país. Varias circunstancias lo hicieron posible. El incentivo de crecimiento de algunos generadores relevantes que veían en la termoelectricidad una vía factible para competir con la hidroelectricidad dominante; los acuerdos binacionales suscritos con Argentina; el precio atractivo que presentaba el suministro desde el país vecino; la nueva tecnología disponible en turbinas generadoras más eficientes y la conveniencia de contar con un combustible menos contaminante que el carbón y el diesel.

Para la implementación de los primeros gasoductos se recurrió al marco general de la institucionalidad legal y se dictó nueva normativa para regular a las concesionarias de transporte, en la que, como ya vimos, se incorporó expresamente la obligación de acceso abierto $^{63}$. En esa época se agregaba como factor adicional la "fuente segura de abastecimiento" -elemento que resultó ser de muy corta duración- y que motivó el desarrollo de los 202 proyectos para la construcción de los terminales de GNL, aprovechando los avances en la tecnología que lo hizo posible.

Atendido el involucramiento de empresas extranjeras en cada uno de los eslabones de la cadena, ya sea como socios, proveedores, clientes o financistas, los mecanismos contractuales utilizados reproducen modelos de jurisdicciones con una industria energética más evolucionada que la chilena en ese momento. Invariablemente uno de los legados fue la cláusula take or pay previamente desarrollada en el mercado estadounidense y ya en aplicación en la industria argentina.

Tanto los contratos de suministro y transporte de gas natural suscritos en relación con el proyecto GasAndes en la década de $1990^{64}$, así como los celebrados para hacer posible el terminal de GNL Quintero ${ }^{65}$, incluyeron una regulación de este tipo ${ }^{66}$. Su implicancia es manifiesta en el mercado

${ }^{63}$ DS No 263 de 1995, ya citado que contiene el Reglamento sobre Concesiones para la Distribución y Transporte de Gas. Para un detalle del contexto y regulaciones de este proceso, véase Palumbo (2008).

${ }^{64}$ Véase n. 16 anterior.

${ }^{65}$ En este caso, se distinguen principalmente los contratos de suministro de GNL y los de servicios de terminal (descarga, almacenamiento y regasificación), inicialmente suscritos en 2007.

${ }^{66} \mathrm{Y}$ en algunos casos su variante menos conocida delivery or pay la cual obliga al vendedor a efectuar un pago al comprador en caso de incumplimiento injustificado con- 
eléctrico, siendo las empresas generadoras la demanda sustancial por gas natural en el país. Ninguno de estos proyectos podría haberse materializado si no hubieran contado con el suministro a la industria de la generación como consumo principal. Adicionalmente, empresas generadoras fueron parte de los sponsors que integraron los consorcios o accionistas de las empresas desarrolladoras ${ }^{67}$.

La gran magnitud de las inversiones requeridas para llevar a cabo proyectos asociados al gas natural/GNL, intensivos en capital, hace que el suministro del combustible implique compromisos de largo plazo, donde la principal función de los contratos es la mitigación y transferencia de riesgos y de permitir el retorno y financiamiento de las instalaciones, ya que el pago de los clientes asegura un flujo de ingresos mínimo. Entonces, al igual que en el mercado estadounidense, la estipulación take or pay viene a cumplir en nuestro mercado también un efecto de distribución de riesgos ${ }^{68}$.

No obstante que gran parte de los contratos en esta industria pueden estar sujetos a la ley extranjera, desde el punto de vista de la clasificación civil clásica de los contratos bajo la ley chilena, se puede categorizar a los que contienen una obligación take or pay como un contrato innominado de suministro, bilateral ("las partes contratantes se obligan recíprocamente" ${ }^{69}$ ), oneroso ("tiene por objeto la utilidad de ambos contratantes, gravándose cada uno a beneficio del otro"70), y de tracto sucesivo (el nacimiento, cumplimiento y extinción de las obligaciones se prolonga, sucesiva y periódicamente durante toda la vigencia del convenio), en virtud del cual el vendedor se obliga a poner a disposición un bien, servicio o ambos durante un plazo determinado y el comprador se obliga a pagar en forma periódica una determinada cantidad mínima como contraprestación, sea que utilice o consuma tal producto o servicio, o no lo haga.

También se entiende conmutativo (las partes al momento de perfeccionarlo pueden estimar o pronosticar los resultados económicos que les ocasionará el contrato), pues el Derecho que recibe el cliente consistente en tener a disposición las cantidades del bien según lo requerido, debe mirarse como equivalente de la obligación de pagar el precio $^{71}$. A diferencia

forme a los términos detallados del contrato respectivo, de su compromiso de entregar el gas, como contrapartida a la obligación de take or pay.

${ }^{67}$ Gener (hoy AESGener) en el caso de GasAndes; ENDESA en el caso de GNL Quintero; GDFSuez en el caso de Norandino y GNL Mejillones; GasAtacama en el caso de su gasoducto.

${ }^{68}$ Véase Informe Centro de Energía FCFM (2014), p. 28.

${ }^{69}$ Art. 1439 del Código Civil.

${ }^{70}$ Art. 1440 del Código Civil.

${ }^{71}$ No es posible descartar completamente el caso de algún comprador decepcionado que sostenga que su contrato fue aleatorio (contraprestación es una contingencia incierta 
de alguna doctrina, como Jorge López Santa María y Juan Andrés Orrego Acuña, en nuestra opinión el art. 1441 del Código Civil, no exigiría una supuesta igualdad en las prestaciones de las partes, sino que quiere significar que las mismas se entienden como proporcionales o justificables la una con la otra, de acuerdo con la valoración que le han dado los propios contratantes. Por último, aunque pueden apreciarse ciertas características de una compraventa, esta, sin embargo, exige que el comprador reciba la cosa.

Considerando que el suministro de gas natural por gasoducto en la actualidad es prácticamente inexistente, el análisis que sigue a continuación se centrará en el mercado de contratos de GNL.

\section{Efecto en el mercado eléctrico}

En el mercado de los sistemas eléctricos, los generadores transan energía al costo marginal que el coordinador ${ }^{72}$ respectivo calcula en intervalos horarios, los que dependen de las distintas unidades generadores, despachadas centralizadamente por orden de mérito creciente de sus costos variables que informan las mismas empresas generadoras. El costo marginal horario se determina por el costo variable de la última unidad despachada.

Esto deriva de uno de los principios fundamentales del sistema eléctrico chileno, conforme al cual las instalaciones eléctricas deben sujetarse a coordinación para preservar la seguridad del servicio y para garantizar la operación más económica del conjunto de las instalaciones del sistema. Para estos efectos, el marco regulatorio dispone que todo propietario, arrendatario, usufructuario o quien explote, a cualquier título, centrales generadoras que se interconecten al sistema, estará obligado a sujetarse a la coordinación y a proporcionar la información necesaria y pertinente que el coordinador le solicite para mantener la seguridad global del sistema y optimizar la operación. El marco normativo, asimismo, hace responsable a cada integrante, separadamente, por el cumplimiento de las obligaciones que emanen de la reglamentación ${ }^{73}$.

de ganancia o pérdida), en caso de no haber podido recuperar las cantidades de producto pagadas, pero no recibidas. Esto es de relevancia jurídica, pues la imprevisión solo puede tener cabida en contratos conmutativos. Abeliuk (2001), pp. 70-73.

${ }^{72}$ Ente mandatado por ley para coordinar la operación de las instalaciones eléctricas de cada sistema eléctrico, con las finalidades principales de preservar la seguridad del servicio y garantizar la operación más económica. Hasta el 31 de diciembre de 2016, esta tarea era encomendada a los CDE). Con la dictación de la ley No 20.936 de 2016, la función pasó al nuevo Coordinador Independiente del Sistema Eléctrico Nacional.

${ }^{73}$ Título II bis y art. 149 Ley General de Servicios Eléctricos, DFL No 4 de 2007. Véase también arts. 3, 44 y 47 del DS No 291 de 2008, que contenía el Reglamento de los CDEC. 
"Una asignación de recursos eficiente es aquella que maximiza el bienestar social (...) El CDEC opera el despacho bajo el supuesto de demanda constante en el corto plazo, por lo que la eficiencia económica se conseguiría simplemente minimizando los costos del despacho económico, es decir, suministrando la demanda a mínimo costo variable de operación del parque generador"74.

Lo anterior, exige que el precio igual al costo marginal sea producto de los costos variables reales de operación de cada generador que puedan comprobarse y no ser objeto de una información arbitraria.

Los combustibles son el principal insumo de las generadoras eléctricas y son la parte fundamental de sus costos variables. Estos consideran la suma de los costos de las distintas etapas de la cadena de producción que, en la mayoría de los casos, incluye el precio FOB del combustible fósil, el seguro, el flete marítimo, los derechos arancelarios, las mermas, los gastos financieros, los costos de descarga, de almacenamiento y el transporte terrestre. Los costos variables son costos "evitables" que inciden en las decisiones de producción de los agentes económicos y representan el costo alternativo o de oportunidad a la que se renuncia al hacer uso del combustible (es el valor del combustible en su mejor uso alternativo en ese momento). Al respecto, la teoría económica señala que si un bien no tiene costo de oportunidad u otro uso alternativo mejor, su costo económico es cero. Los costos fijos tienen esta característica, son "inevitables" y no inciden en las decisiones de producción ${ }^{75}$.

Los costos variables que deben considerarse son aquellos relacionados con la cadena de suministro en que se involucra la firma generadora y los que deriven de las condiciones contractuales. Sin embargo, las empresas que utilizan GNL como combustible, pueden enfrentar una incertidumbre considerable respecto de la proyección del despacho económico de sus unidades $^{76}$. Esto se debe a que los contratos de uso generalizado utilizados

${ }^{74}$ Informe DICTUC (2011), p. 15.

${ }^{75}$ Véase Informe Centro de Energía, FCFM (2014), pp. 22-26 y 38-44.

76 "El GNL es un combustible importado sin un suministro continuo, con condiciones de abastecimiento mucho más rígidas que para los otros combustibles, inherentes a un mercado en crecimiento que intenta financiar sus costos de desarrollo mediante contratos de largo plazo muy inflexibles y donde la flexibilidad tiene un muy alto precio. En el mundo la mayoría del volumen comercializado de GNL se realiza con contratos que incorporan cláusulas Take or Pay. Con un almacenamiento caro y por ende restringido, que sumado a los escasos mercados alternativos establece importantes restricciones para su uso. Estas restricciones conducen a un costo económico relevante para el despacho dependiente de las condiciones de escasez o abundancia relativa de corto plazo del GNL y que no necesariamente corresponda a los costos nominales asociados a los contratos". Informe DICTUC (2011), p. 84. 
presentan rigideces importantes en cuanto a la programación anticipada del suministro (i.e. Debe hacerse el año previo al consumo), atendidas las limitaciones de almacenamiento y restricciones de logística del transporte y a la inclusión de cláusulas take or pay.

En la práctica, lo anterior significa que la valorización de los costos variables que se asigne respecto de los suministros de GNL que se declaren por las empresas generadoras, va a depender de las condiciones contractuales de cada una de ellas y de si las mismas permiten algún uso alternativo para el combustible. Así, en los contratos que permiten flexibilidades tales como redireccionamiento o cancelación de embarques, transferencia a terceros o exportación a otros países, los costos variables deberían valorizarse al costo unitario del mismo, pero, en cambio, en los contratos rígidos que no permiten usos alternativos, el costo variable debe ser valorizado lo suficientemente bajo como para asegurar su despacho y uso, pues de lo contrario se corre el riesgo de perder ese gas, lo cual es socialmente no deseable.

\section{Discrepancia en el Panel de Expertos}

El tratamiento de las cláusulas take or pay en los contratos de suministro de GNL y su implicancia en el proceso de declaración de costos, para

206 efectos del mercado eléctrico, fue objeto de una discrepancia ante el $\mathrm{Pa}$ nel de Expertos en el cual se hicieron parte algunas empresas mineras y generadores del SING.

En mayo de 2011 CODELCO planteó una discrepancia respecto del título IV, art. 8 "Estructura del costo del gas natural", del Procedimiento DO del CDEC-SING, destinado a regular la forma de entregar, validar y actualizar la información sobre los costos de los combustibles utilizados por las centrales generadores del SING. Específicamente, CODELCO solicitó que los generadores transparentaran la información al CDECSING respecto de contratos que consideraran condiciones take or pay, respecto de términos de entrega y disponibilidad. Para ello pidió que se agregara un inciso al art. en cuestión que señalaba:

"Adicionalmente, se deberá informar si existen contratos bajo modalidad Take or Pay suscritos en el suministro, transporte, regasificación y/o almacenamiento de gas natural, puntos y condiciones de entrega y los períodos en que se aplican”.

CODELCO objetó el nuevo Procedimiento DO por cuanto este no consideró la posibilidad de solicitar a las empresas generadoras todos los antecedentes e información que, en su parecer, debía incorporarse en la declaración de costos de combustibles de las centrales generadoras, tales 
como: modalidad, plazo, vigencia y otros elementos de similar naturaleza que permitan que la programación preserve la seguridad del servicio instantáneo del sistema y minimice su costo actualizado de operación y de falla para un horizonte predeterminado, según lo disponen las normas legales y reglamentarias.

Sostuvo CODELCO que correspondía entregar información amplia, completa y fidedigna en relación con los costos de los combustibles de las centrales generadoras del SING. Esta información, se debe entregar con el fin que la DO cumpla cabalmente con sus funciones y, además, para que sea conocida por todos los integrantes del CDEC-SING para resguardar sus derechos y velar por sus legítimos intereses.

La reclamante agregó que no se debía confundir la validación con el derecho a acceder a una completa información sobre los costos de los combustibles, que es el elemental derecho a conocer los antecedentes y fundamentos de decisiones que impactan en los legítimos intereses de todos los integrantes del CDEC, tal como consagra el art. 9 del reglamento de los CDEC. El proceso de validación de la información no resolvería el problema, ya que lo que se valida es la información entregada y la DO no puede descansar en que las empresas integrantes del CDEC-SING acudirán ordinariamente a la verificación de la información (procedimiento, por lo demás, extraordinario), para cumplir su obligación esencial de "garantizar la operación más económica para el conjunto de instalaciones", señalada en la ley, pues ello implica el traspaso hacia los demás integrantes del CDEC-SING de las responsabilidades propias del CDEC.

Extendió CODELCO su argumentación a la supremacía de normas de orden público por sobre normas contractuales de confidencialidad, a propósito de los argumentos expuestos por los oponentes y sostuvo que es en la actividad de generación eléctrica, especialmente regulada, donde, para cumplir sus propias normas y objetivos (v.gr. el despacho económico), se hace absolutamente necesario entregar y conocer la misma información. Tanto los generadores como sus suministradores, celebraron los contratos con pleno conocimiento de estas normas que, en determinadas circunstancias, obligarían a la entrega al organismo de coordinación de cierta información.

La DO del CDEC-SING, por su parte, hizo presente que ella era independiente y a quien correspondía definir la información necesaria y pertinente requerida para sus procesos o productos a través de sus procedimientos. Advirtió, además, la inconveniencia de desnaturalizar al CDEC y entenderlo como el depositario de las condiciones -o modalidades-contractuales de los distintos insumos de generación que se utilizan para las decisiones de operación, ya que tampoco lo es en el ámbito específicamente eléctrico. Por último, afirmó que los ajustes realizados en el Nuevo Proce- 
dimiento DO, se refieren a aspectos específicos, sin renunciar a principios tales como: responsabilidad de información de las empresas, mecanismo de validación y autorregulación, respaldo y trazabilidad de costos informados, pool de costos declarados, impidiendo mercado de oferta o autodespacho, entre otros. La DO solicitó al Panel de Expertos rechazar la discrepancia formulada.

GasAtacama expuso que la discrepancia presentada por CODELCO y apoyada por Escondida, parte de premisas erradas. Indicó que el procedimiento impugnado otorgaba certeza a los distintos actores en relación con la efectividad de los costos, por cuanto obliga a cada empresa a declararlos en forma responsable, con un respaldo fidedigno, sujeto a un procedimiento que permite a la DO acceso a toda la información necesaria para realizar la verificación de los costos y fiscalizado por la Superintendencia. Para GasAtacama, en un mercado de "costos declarados" lo que debe ser de público conocimiento es el costo variable del combustible y no las condiciones contractuales y comerciales. Es falso, a su juicio, que los contratos take or pay tengan, en forma permanente, un costo variable de combustible igual a cero. Explicó la empresa que, en la modalidad contractual take or pay, existe una serie de flexibilidades en el uso del gas natural, y que solo una vez agotada la posibilidad de dar un uso alternativo al gas natural se puede sostener que el costo de este es nulo. Agregó que la modificación que proponía CODELCO era discriminatoria, ya que aplicaría solo para el gas natural, omitiendo al carbón, el cual también tiene contratos con cláusulas de take or pay en la cadena de suministro. A su juicio, se equivocó CODELCO, pues el Director de Operación no tiene facultades de fiscalización, sino que de verificación de precios actuando como ministro de fe, cuando los precios declarados son observados por alguna de las empresas integrantes; quien realiza las funciones de fiscalización es la SEC. Afirmó que se pretendía llevar al ámbito público, información de las empresas que es de carácter privado.

Para E-CL, el CDEC tenía facultades de requerir y validar la información entregada para efectos de respaldo de la respectiva declaración de costos de combustibles por parte de las empresas generadoras. Advirtió, asimismo, de las sanciones contempladas por la legislación eléctrica para los supuestos incumplimientos de esta normativa, así como de la facultad de fiscalización de la SEC. Destacó la instancia de validación de la información proporcionada por las empresas ante el Director de Operación que está prevista en el procedimiento. Las exigencias de información que propuso CODELCO en su visión serían redundantes e inútiles, pues las empresas generadoras tienen la obligación de informar las componentes variables de los costos de sus combustibles; porque requería que se haga pública información contractual de carácter estratégico referente a las po- 
líticas comerciales de las empresas y de carácter confidencial para terceros que no sean las autoridades con facultad de conocer dicha información.

La propuesta de CODELCO, a su juicio, obstruía, desincentivaba y creaba barreras a los proveedores mundiales de gas natural licuado para venderlo al mercado chileno, haciendo notar E-CL el riesgo de ultrapetita y precisando que la solicitud de CODELCO apuntaba solamente a incluir un párrafo referido a entregar información contractual en forma pública y que no era la discrepancia una instancia de decisión respecto de si los contratos celebrados en modalidad take or pay son en sí mismos costos fijos. En opinión de la interviniente, el axioma simplista de que todo contrato take or pay es un costo fijo y que por ello redundaría en menores costos para los clientes, es falso. E-CL expuso al respecto algunas características de la industria del gas donde concurren diferentes formas en la logística de suministro, desde uno rígido a uno flexible y la presencia de derechos contractuales del comprador que permiten flexibilidades en el consumo de GNL. Rechazó también que exista semejanza entre un almacenamiento de GNL y un embalse de agua, porque el agua está confinada en el embalse sin usos alternativos más que la producción de la electricidad, mientras que el GNL almacenado tiene innumerables usos alternativos.

Finalmente, Minera Escondida confirmó la procedencia de la posición planteada por CODELCO y la necesidad de que se introduzca el párrafo propuesto por ella. En cuanto a la decisión del Panel, aclaró que la discrepancia se centraba en la objeción a un procedimiento del CDEC-SING y, en consecuencia, el dictamen del Panel no se ve limitado exclusivamente a optar por una u otra alternativa en discusión y tiene plena libertad para analizar el fondo de la disputa y proponer, en su mejor entender, una solución acorde con su análisis. Concluyó expresando que las partes han estado contestes en la existencia de contratos take or pay en el suministro de gas natural licuado, y en que esta característica constituye un costo fijo, difiriendo solamente en la porción del costo que podría ser variable.

Del análisis, el Panel concluyó lo siguiente:

i) La ley le confiere a la información un valor estratégico para la coordinación y operación del sistema eléctrico y no establece limitaciones, ni excepciones para el aporte de información a los fines de la coordinación.

ii) La ley ha establecido procedimientos, instancias y organismos para la entrega, recepción y uso apropiado de la información.

iii) "La información, en el contexto del CDEC, es pública para todos los coordinados como un factor consustancial a su propio estatuto de coordinados y está asociada al cumplimiento de los fines de la confiabilidad del sistema y de producción al mínimo costo”. 
...Por ende:

"cualquier condición o circunstancia que incida en los costos de la producción, así como en la seguridad y confiabilidad del sistema, hace que ella sea necesaria y pertinente para el conocimiento tanto del organismo coordinador como de los coordinados".

iv) No es controvertido por las partes que la modalidad take or pay de los contratos, en distintos grados, incide en los costos variables que se incurren en la producción de las plantas de generación y eso justifica que dicha modalidad sea informada al CDEC.

v) Dada

"la conexión transitiva entre costo marginal y costos variables, estos últimos deben corresponder al costo en que se incurra en la producción de una unidad adicional de energía en cada central. A este efecto, los costos variables son determinables por un conjunto de factores, para lo cual debe analizarse la modalidad contractual”.

vi) No es admisible que las empresas puedan informar o declarar costos a su conveniencia y por ello la ley consagra como infracción gravísima la entrega de información falseada que pueda afectar el normal funcionamiento del mercado o los procesos de regulación de precios.

vii) "La instancia de validación que se contiene en el Nuevo Procedimiento DO no es suficiente por sí misma como solución al problema, dado que si ella no puede llegar al núcleo real de la información su propósito verificador se agota en la información formal”.

Como consecuencia, el Panel, por unanimidad, acordó dar lugar a la solicitud y dispuso agregar en el art. 8 del Procedimiento DO "Costos de combustibles de las centrales generadoras del SING", un inciso final con el texto propuesto por CODELCO ${ }^{77}$.

${ }^{77}$ Discrepancia CODELCO et al., $\mathrm{N}^{\mathrm{o}}$ 03-2011. Con posterioridad a este caso, se han presentado ante el Panel las discrepancias $\mathrm{N}^{\circ}$ 02-2015 y No $04-2016$ relativas a información requerida de contratos de suministro de combustible y sobre cálculo de costo de combustibles, respectivamente, ambas por AES Gener, pero que fueron desistidas antes de la vista de la causa. 


\section{Acuerdos del CDEC-SIC}

Como hemos visto, el principio de la operación al mínimo costo y la consecuente obligación de declaración de costos de combustible por parte de los generadores coordinados, forma parte esencial del sistema eléctrico de "pool" existente en nuestro país ${ }^{78}$.

Las direcciones de cada CDEC establecían mecanismos de trabajo a través de procedimientos, los cuales debían ajustarse a la normativa y estaban destinados a determinar los criterios, consideraciones y requerimientos de cada una de ellas para cumplir con las tareas que les son propias. En afinidad con el marco reglamentario, el CDEC-SIC emitió un "procedimiento de declaración de costo de combustibles", el cual, entre otras materias, contiene las pautas para determinar la estructura de costos del gas natural y GNL, imponiendo las condiciones y requisitos a ser informados por los distintos generadores que los utilicen en sus plantas ${ }^{79}$.

En particular, en su art. $8^{\circ}$, dispone:

"Adicionalmente, se deberá informar si existen contratos bajo modalidad Take or Pay suscritos en el suministro, transporte, regasificación y/o almacenamiento de gas natural, puntos y condiciones de entrega y los períodos en que aplican. En cuyo caso se deberán informar los costos incurridos, volúmenes comprometidos y períodos correspondientes".

Cabe destacar que la primera parte de dicho artículo es idéntica a la que el Panel de Expertos ordenó agregar al procedimiento del CDECSING al resolver la discrepancia descrita en el punto precedente. El procedimiento del CDEC-SIC no asigna un valor a los combustibles, ya que su función es fijar un criterio general para la determinación de los costos, destinado a perdurar en el tiempo.

Siendo parte de sus funciones velar por el cumplimiento de la reglamentación vigente, así como también por la operación segura y eficiente del sistema eléctrico, estableciendo los criterios generales para el cumplimiento de dicho objetivo ${ }^{80}$, mediante acuerdo adoptado por su directorio, el CDEC-SIC dispuso que, a efectos de optimización de la operación del sistema, el costo variable combustible de las unidades que utilicen

${ }^{78}$ Véase n. 73.

${ }^{79}$ Informado favorablemente por la Comisión Nacional de Energía, mediante res. $\mathrm{N}^{\circ} 495$ del 17 de junio de 2016 y disponible en https://sic.coordinadorelectrico.cl/informes-ydocumentos/fichas/procedimientos-aprobados-por-la-cne/attachment/res-ext-n-495/ [fecha de consulta: abril 2017].

${ }^{80}$ Art. 25 del DS No 291 de 2008, que contenía el reglamento de los CDEC. 
gas disponible bajo el esquema TAKE OR PAY, será igual a cero durante el periodo de programación ${ }^{81}$.

Conforme al contenido de la referida acta, el origen de la disposición provendría de la necesidad de lograr que efectivamente el ente coordinador pudiera contar con la información correspondiente al costo variable y disponibilidad de cada central térmica, en forma previa a la operación, para lo cual se requería un criterio general a adoptar. Como fundamento de lo anterior, se argumentó que ello daba cumplimiento a las tareas encomendadas por la normativa vigente al CDEC, en el sentido de ejercer su facultad de tomar

"todas aquellas medidas que fueren necesarias (...) para asegurar la función específica de efectuar una operación segura y eficiente”.

De la discusión reflejada en el documento, se da a entender que se buscaba evitar casos en que los valores informados de manera eventual pudieran haber sido ajustados con posterioridad a la programación.

Se agrega que lo expuesto estaría en línea con otros criterios generales previamente acordados por el mismo directorio y "destinados a orientar el uso de los recursos primarios de las centrales del SIC", con el objetivo de 212 velar por su operación segura y eficiente. En virtud de este criterio previo, se entregaba flexibilidad para la optimización del despacho, estipulando que en los eventos de disponibilidad limitada del recurso primario que no permita la generación a plena capacidad durante el día, el perfil de generación horario o diario será establecido por la Dirección de Operación, de tal forma de minimizar los costos de operación y falla del sistema ${ }^{82}$.

De esta forma, el directorio del CDEC-SIC fijó un criterio general para la valorización de los costos variables del gas disponible bajo un esquema que se declare como take or pay, independiente del uso alternativo que efectivamente se le pueda dar o no a ese combustible al momento

${ }^{81}$ Acta sesión ordinaria N OR-1-2016 del directorio CDEC-SIC, del 13 enero 2016, pp. 18-21. El referido acuerdo señala: "Para efectos de la optimización de la operación, la DO debe disponer, previamente y para el período correspondiente, del costo variable combustible y del costo variable no combustible de cada una de las centrales termoeléctricas, en cifras nominales en US\$/MWh. Asimismo, deberá contar para todo el período programado de la información de disponibilidad de combustible para cada una de estas unidades generadoras, sea a nivel horario, diario o semanal. Para el gas disponible bajo el esquema “consúmalo o páguelo"(take or pay) para el período de programación el costo variable combustible de la unidad que lo utilice es igual a cero. Cualquier cambio en lo informado en los costos variables será utilizado para fines de despacho solo luego de ser incluido en una nueva programación Diaria y Semanal, según corresponda”.

${ }^{82}$ Acta sesión extraordinaria $\mathrm{N}^{\circ}$ EX-4.1-2015 del directorio CDEC-SIC, del 24 abril 2015, pp. 4-6. 
de su declaración de costos, lo cual podría deberse a que el directorio consideraba equivalentes ambos conceptos. La duda que surge es si por la vía del proceso de verificación de costos que consideraba el mismo procedimiento regulado por el CDEC-SIC podría desvirtuarse el costo variable predefinido si se acreditaba que el mismo no era real.

\section{Norma técnica de programación}

La Comisión Nacional de Energía, organizó un grupo de trabajo privado que comenzó a sesionar el 10 de septiembre de 2015, integrado solo por personas invitadas especialmente por el mismo organismo, con el fin de contar con una propuesta de modelación eficiente de las restricciones de precio y disponibilidad del GNL, según sus propias definiciones ${ }^{83}$.

Como resultado de este trabajo, el regulador dictó la "Norma técnica para la programación y coordinación de la operación de unidades que utilicen GNL regasificado" "84, la cual tiene por objetivo establecer las exigencias de información, procedimientos, metodologías, mecanismos y condiciones de aplicación que resulten necesarias para la programación y coordinación de la operación de unidades de generación que utilicen GNL regasificado, incluyendo los criterios para la determinación del costo variable y disponibilidad del insumo, y que el coordinador del sistema deberá seguir para la programación y despacho de las centrales que utilicen tal combustible.

De conformidad con esta norma, se exige a toda persona que explote a cualquier título una o más centrales de generación eléctrica que utilicen GNL regasificado, informar al coordinador los términos principales de sus respectivos contratos de suministro de gas, indicando, entre otras, si está sujeto a condiciones de take or pay ${ }^{85}$ e identificando las componentes que permiten determinar el costo variable de operación de las centrales, que son básicamente los mismos estipulados en el "Procedimiento de declaración de costo de combustibles" referido en el párrafo precedente. Asimismo, las generadoras deberán detallar cualquier flexibilidad o restricción que impongan los contratos de suministro respectivos, tales como: interrupción, cancelación o reventa del suministro, todo ello sujeto a un proceso de confirmación de veracidad y exactitud de los antecedentes por parte del coordinador y a la eventual acción de la Superintendencia del ramo en caso de datos falsos o incompletos.

${ }^{83}$ Véase www.cne.cl/nuestros-servicios/grupo-de-trabajo-modelacion-de-restriccionespara-modelamiento-del-gnl/ [fecha de consulta: junio 2016].

${ }^{84}$ Resolución exenta $N^{\circ} 638$ de 2016.

${ }^{85}$ Término que se define en el documento como: “Obligación contractual de pagar por una cantidad de GNL o GNL Regas preestablecida, sea ésta utilizada o no”. 
En lo que respecta a la programación de la operación propiamente tal, prevé que las generadoras deberán remitir en forma mensual al coordinador una declaración vinculante sobre su disponibilidad, costos y flexibilidad del suministro para una ventana móvil de doce semanas consecutivas. Se considerará que un volumen tiene condición inflexible, si este no puede ser destinado a un uso distinto al de generación del sistema eléctrico nacional en la ventana móvil, sin causar un perjuicio económico relevante calificado y justificado como tal por la propia empresa generadora declarante. En forma adicional, las generadoras deberán declarar semanalmente al coordinador el costo variable de cada una de sus unidades para los próximos siete días, costo que tendrá que ser consistente con los antecedentes de disponibilidad y costos informados en la declaración enviada para la ventana vigente.

Las unidades que se encuentren operando con un volumen en condición de suministro inflexible, deberán ser consideradas para efectos del cálculo del costo marginal del sistema con un costo variable combustible igual a cero y sus inyecciones de energía serán valorizadas al costo marginal del sistema. Sin perjuicio de lo anterior, el coordinador deberá optimizar la programación de la operación de dichas unidades de manera de minimizar el costo total de operación y falla del sistema eléctrico durante el 214 correspondiente periodo.

En el caso de un volumen en condición de suministro flexible, el coordinador deberá optimizar la generación de energía eléctrica de dicha unidad considerando su costo variable de operación dentro de la ventana de información, de manera de minimizar el costo total de operación y falla durante dicho periodo y serán consideradas en el cálculo del costo marginal del sistema, conforme a las mismas disposiciones establecidas para las restantes centrales que se encuentren operando en el sistema que no presenten condición inflexible.

\section{Take or pay y flexibilidades}

De lo visto en los capítulos anteriores, se aprecia una variación entre el criterio impuesto en la resolución 638/16 y en los procedimientos utilizados por los CDEC ya extintos. La referida resolución reemplaza a tales procedimientos en esta materia y en efecto agregó un elemento subjetivo en la ecuación al diferenciar la condición de suministro de cada contrato como flexible o inflexible.

Así, conforme a la norma no basta que un determinado contrato incluya el suministro bajo condiciones take or pay, sino que el suministro debe estar privado de otros usos alternativos a la generación eléctrica que no causen un perjuicio económico para su titular. De esta forma, se recogen 
algunos argumentos presentados durante la discusión de la discrepancia No 03-2011 ante el Panel de Expertos como se expuso precedentemente.

En este sentido, los contratos de suministro en el mercado del gas natural, en mayor o menor medida contienen mecanismos de flexibilidad que permiten la cancelación de determinados volúmenes de carga al año o redireccionar el mismo a otros destinos, sin perjuicio de la posibilidad de recurrir al mercado secundario para su reventa a terceros. Sin embargo, el tamaño y la estructura del mercado chileno reducen esas flexibilidades en términos muy significativos, dada su falta de profundidad y las complejidades y limitaciones de logística y usos alternativos para el producto. Debemos recordar que el principal destino del gas natural/GNL en Chile es ser utilizado como combustible para la generación de electricidad y que el sistema de redes de gasoductos presenta una capacidad limitada.

Comparativamente, en el caso del mercado eléctrico como tal, se utiliza la práctica no generalizada del redireccionamiento, en virtud de la cual las partes de un contrato de suministro de electricidad pueden acordar que se descuente del precio el volumen de electricidad producida efectivamente por el generador, pero no consumida por el cliente en un determinado periodo contractual.

La referida cláusula aplica en casos de suministro de energía cuyos contratos contienen compromisos de cargos fijos para el cliente, que constituyen la base del flujo económico que justifica la inversión por parte del suministrador de uno o más activos específicos que sirven para proveer al mismo, estipulación que además requiere se produzca una inyección efectiva de energía al sistema por parte de tales activos. Sería un error concluir que por solo hecho de existir el mecanismo del mercado spot en un sistema eléctrico, tales redireccionamientos se permiten y se efectúan respecto de cualquiera y toda planta en el portafolio de unidades de generación de un determinado generador, cada vez que un cliente no consume efectivamente la cantidad de electricidad por él contratada.

\section{Conclusiones}

La necesidad de protegerse de algunos riesgos que se consideraban relevantes y darle mayor equilibrio a las obligaciones entre las partes fue la razón del surgimiento de este mecanismo contractual foráneo, de origen anglosajón, que denominamos la "cláusula take or pay". Lo interesante es que, si bien entre las principales contingencias hubo razones económicofinancieras, también se sostiene la existencia de factores en la política de regulación como coadyuvantes. 
Con el mismo objetivo, pero en otro contexto, la estipulación se instala en el mercado de la energía en Chile desde mediados de la década de 1990, de modo de hacer factible la implementación y operación del nuevo mercado emergente del gas natural y su uso en la industria de la generación eléctrica. No obstante la virtual desaparición del mercado de suministro desde Argentina, la estructura se ha perpetuado en la cadena contractual del GNL.

Siendo uno de los principales combustibles utilizados para la generación termoeléctrica, atendidas su disponibilidad, mejores características ambientales y precio competitivo, el mismo ha tenido una incidencia relevante en la determinación de los costos variables que deben ser declarados para los efectos del despacho de las unidades en el sistema eléctrico y del consecuente costo marginal, lo cual presenta complejidades derivadas de la estructura del mercado del GNL y de su principal característica de "rigidez" de su esquema contractual. En el mercado estadounidense, tal rigidez llevó a una ola de litigios extensos y muy costosos.

Como vimos, lo anterior puede presentar incertidumbres para la planificación operacional de las plantas, así como también para la administración de los costos financieros de los involucrados y tampoco ha estado exenta de controversias entre integrantes del mercado eléctrico.

216 Es posible presumir que con el objetivo de sumar certeza al proceso, el directorio del CDEC-SIC haya adoptado el criterio analizado conforme al cual el costo variable combustible de las unidades que utilicen gas disponible bajo el esquema take or pay, será igual a cero durante el periodo de programación. De esta manera, pareciera adoptar una interpretación objetiva formal, distanciándose del análisis económico que plantea la necesidad de agotar los eventuales usos alternativos que puedan darse a un bien en forma previa a considerar su costo de oportunidad igual a cero. La importancia del acuerdo es que fija una regla aplicable en línea con la práctica más generalizada de mercado, en el sentido de que el costo de oportunidad del combustible sería el correcto criterio de su valorización en contratos con condiciones take or pay.

Desde el punto de vista de Derecho, sin embargo, pueden plantearse interrogantes respecto de su aplicación futura y de la necesidad de desarrollar mecanismos de flexibilización contractual que permitan controlar situaciones extremas que inciten a las partes a dejar de honrar los acuerdos celebrados. ¿Qué implicancias puede tener para la interpretación de esta cláusula y el contrato subyacente, por ejemplo, en caso de que alguna de las partes reclame que ha sufrido un cambio sustancial e imprevisto en las circunstancias de modo que se ha hecho de tal manera onerosa su obligación que no resulta equitativo seguir dándole cumplimiento? 


\section{Bibliografía CitADA}

Abeliuk Manasevich, René (2001). Las obligaciones. Santiago: Editorial Jurídica de Chile.

Alessandri Rodríguez, Arturo (1988). Derecho Civil. De los contratos. Santiago: Editorial Jurídica Ediar-Conosur.

Bahamondez Prieto, Felipe (2008). "Fallo Gasatacama: El cambio de circunstancias en los contratos. Quo Vadis?", sentencias destacadas 2008. Anuario de Doctrina y Jurisprudencia, Libertad y Desarrollo. Santiago.

Coderch, Pablo Salvador (2009). "Alteración de circunstancias en el art. 1213 de la Propuesta de Modernización del Código Civil en materia de Obligaciones y Contratos". Revista InDret. Vol. 4. Barcelona. Disponible en www.indret. $\mathrm{com} / \mathrm{es} /$ ?ed=41 [fecha de consulta: mayo de 2016].

Coffey, RodrickJ. (1999). "Fairness is in the Eye of the Beholder: The Conflicting Interpretations of the Correct Measure of Damages for Breaches of Natural Gas Contracts Containing Take-or-Pay Provisions”. Brigham Young University Journal of Public Law. Vol. 14. Utah.

Cooter, Robert \& Thomas Ulen (2008). Law and Economics. Fifth Edition. London: Pearson Addison Wesley.

Diez-Picazo, Luis (1996). Fundamentos del Derecho Civil Patrimonial. I. Introducción. Teoría del Contrato. $5^{\text {a }}$ edición. Madrid: Civitas.

Frischmann, Brett \& Waller Spencer Weber (2006). "Essential facilities, Infrastructure and Open Access", working paper.

Informe Centro de Energía, FCFM, Universidad de Chile (2014). "Análisis Económico del Despacho Eléctrico de Generadores con Contratos de Suministro de Combustible GNL Take or Pay", diciembre. Disponible en www.cne.cl/ estudios/hidrocarburo/ [fecha de consulta: junio 2016].

Informe DICTUC (2011). "Análisis de la Estructura de Costos del GNL Regasificado", diciembre. Disponible en www.cne.cl/estudios/hidrocarburo/ [fecha de consulta: julio 2016].

KNowles, Gearold L. (2003). "Liquified Natural Gas: Regulation in a Competitive Natural Gas Market”, Energy Law Journal. Volume 24, № 2. Oklahoma.

Looper, Scott (2011). "Take or Pay Crisis V2.0: What Wind Power Generators and Providers Failed to learn from Gas Pipelines' 1980 Dilemma”. Houston Journal of International Law. Vol. 33. $\mathrm{N}^{\mathrm{o}} 2$. Houston, Texas.

Lute, Josh (2007). "LNG Terminals: Future or Folly?". Willamette Law Review. Vol. 43. Oregon.

McArthur, John Burrit (1992). "The Take or Pay Crisis: Diagnosis, Treatment and Cure for Inmorality in the Marketplace". New Mexico Law Review, Vol. 22, Albuquerque. Spring

McArthur, John Burrit (1997). "Anti-trust in the New (De)Regulated Natural Gas Industry”. Energy Law Journal. Vol. 18, N 1. Washington D.C. 
McGrath, Jerome J. (1984). "Natural Gas, in Turmoil and Transition". Journal of Energy Law and Policy. Vol. 5. Utah.

Medina, J. Michael, Gregory A McKenzie \& Bruce M. Daniel (1986). "Take or Litigate: Enforcing the Plain Meaning of the Take-or-Pay clause in Natural Gas Contracts". Arkansas Law Review. Vol. 40. N 185. Arkansas.

Medina, J. Michael (1991). "The Take-or-Pay Wars: A Cautionary Analysis for the Future". Tulsa Law Review. Vol. 27, Issue 2. Tulsa, Oklahoma.

Momberg Uribe, Rodrigo (2011). The Effect of a Change in Circumstances on the Binding Force of Contracts. Thesis, Utrecht: Utrecht University.

Palumbo Ossa, Blanca (2008). "Marco Normativo que Permitió la Llegada del Gas Natural a Chile", en Instituto Libertad y Desarrollo. Gas Natural: Lecciones de una Crisis, Santiago: Libertad y Desarrollo.

Pierce, Richard J. (1988). "Reconstituting the Natural Gas Industry from Wellhead to Burnertip". Energy Law Journal. Vol. 9, $\mathrm{N}^{\circ}$ 1. Washington D.C.

Pitofsky, Robert, Donna Patterson y Jonathan Hooks (2002). "The Essential Facilities Doctrine under United States Antitrust Law", Antitrust Law Journal. Vol. 70. Chcago, Illinois.

Rencoret Gutiérrez, Pedro (2010). La Doctrina de las facilidades esenciales ante el Tribunal de Defensa de la Libre Competencia. Memoria de prueba. Santiago: Universidad de Chile. Facultad de Derecho.

218 Sepúlveda Rodríguez, Enrique (2010). Sistema y Mercado Eléctricos. $1^{\mathrm{a}}$ edición. Santiago: Legal Publishing Chile.

Ugarte Soto, Alfredo (2013). "Facilidades Esenciales y Abuso de Posición Dominante". Revista de Derecho Universidad Católica del Norte, $\mathrm{N}^{\circ} 2$. Antofagasta.

\section{Normas citadas}

DS No 263, del Ministerio de Economía, Reglamento sobre Concesiones Provisionales y Definitivas para la Distribución y el Transporte de Gas. Diario Oficial, 8 de julio de 1995.

DFL N ${ }^{\circ}$, del Ministerio de Economía, Ley General de Servicios Eléctricos. Diario Oficial, 5 de febrero de 2007.

DS No 291, del Ministerio de Economía, Reglamento de los CDEC. Diario Oficial, 4 de agosto de 2008.

Ley No 20.936, que establece Nuevo Sistema de Transmisión Eléctrica y crea Coordinador Independiente del Sistema Eléctrico Nacional. Diario Oficial, 20 de julio de 2016.

Resolución Exenta $\mathrm{N}^{\circ}$ 638, del Ministerio de Energía, Norma Técnica para la Programación y Coordinación de la Operación de Unidades que utilicen GNL. Diario Oficial, 2 de septiembre de 2016. 


\section{Jurisprudencia citada}

\section{Chile}

Gasatacama v. Elecda et al., fallo arbitral dictado por el árbitro Ricardo Peralta Valenzuela del 24 de enero de 2008, no publicado, puede verse en BAHAMONDEZ (2008).

CODELCO et al., discrepancia ante Panel de Expertos $\mathrm{N}^{\circ}$ 03-2011, expediente disponible en www.panelexpertos.cl/discrepanciastramitadas.php [fecha de consulta: mayo de 2016].

AESGener et al, discrepancia ante Panel de Expertos $\mathrm{N}^{\circ}$ 02-2015, expediente disponible en www.panelexpertos.cl/discrepanciastramitadas.php [fecha de consulta: junio 2016].

AESGener et al., discrepancia ante Panel de Expertos $N^{\circ}$ 04-2016, expediente disponible en www.panelexpertos.cl/discrepanciastramitadas.php [fecha de consulta: junio 2016].

\section{Estados Unidos}

Pennsylvania v. West Va., Corte Suprema, 262 US 553 (1923).

Missouri v. Kansas Gas Co., Corte Suprema, 265 US 298 (1924).

Public Utilities Comm. v. Attleboro Steam \& Elec Co., Corte Suprema, 273 US 83 (1927).

Interstate Natural Gas Co. v. Federal Power Commission, Corte Suprema, 331 US 682 (1947).

Phillips Petroleum Co. v. Wisconsin, Corte Suprema, 347 US 672 (1954).

Eastern Airlines Inc v. McDonnell Douglas Corp, Corte Federal de Apelaciones, 532 F.2d 957 (5th Cir. 1976).

Aluminum Co of America v. Essex Group Inc., Juez de Distrito, 499 F. Supp. 53 (Pennsylvania, 1980).

International Minerals \& Chemicals Corp. v. Llano Inc, Corte Federal de Apelaciones, 770 F.2d 879 (10th Cir 1985).

Challenger Minerals Inc v. Southern Natural Gas Co, Corte Estatal, 84-C-357E (Oklahoma, 1986).

Northern Indiana Public Services Co v. Carbon County Coal Co, Corte Federal de Apelaciones, 799 F.2d 265 (7th Cir. 1986).

Preston Oil v. Transcontinental Gas Pipeline Corp, Juez de Distrito 19, 294 (Louisiana, 1986).

Golsen v. ONG Western Inc, Corte Estatal, 756 P.2d 1209 (Oklahoma, 1988).

Hanover Petroleum Co v. Tenneco, Corte Estatal, 521 So.d2 1234 (Louisiana, 1988).

Atlantic Richfield Co. v. ANR Pipeline Co., Corte Estatal, 768 S.W. 2d 777 (Texas, 1989). 
(U) Alaska Airlines, Inc. v. United Airlines, Inc., Corte Federal de Apelaciones, 948 F.2d 536 (9th Cir. 1991).

Colorado Interstate Gas Co, v. Chemco Inc, Corte Estatal, 833 P. 2d 786 (Colorado, 1992). 